\title{
Estimativa de recarga da Bacia do Rio das Fêmeas através de métodos manuais e automáticos
}

\author{
Ana C. L. S. Albuquerque ${ }^{1} \&{\text { Henrique M. L. } \text { Chaves }^{2}}^{2}$
}

\section{RESU MO}

$\mathrm{N}$ a região do oeste baiano, na qual se encontra a bacia do Rio das Fêmeas, a água subterrânea tem sido progressivamente procurada como fonte de abastecimento, haja vista a baixa densidade de drenagem da região e a crescente demanda por água, sobremaneira para projetos de irrigação. 0 objetivo do presente estudo é, a partir de dados de vazão, calcular a recarga da água subterrânea por meio de duas metodologias: Arnold \& Allen (1999) e Rutledge \& Daniel (1994), para o período de 1977 a 2007. A precipitação média anual para a bacia do Rio das Fêmeas foi de $1121,83 \mathrm{~mm}$ ano ${ }^{-1}$ e a vazão média anual igual a 50,28 $\mathrm{m}^{3} \mathrm{~s}^{-1}$, ambas apresentando tendência de queda significativa ao longo dos anos. As taxas de recarga foram de $4 \%$ da P total (Arnold \& Allen, 1999) e de $17 \%$ (Rutledge \& Daniel, 1994). Com referência ao escoamento de base (aproximadamente $250 \mathrm{~mm} \mathrm{an0^{-1 }}$ ), o último método mostrou-se melhor na estimação da recarga.

Palavras-chave: recarga da água subterrânea, hidrograma de recessão, hidrologia

\section{Estimates of the recharge in the Femeas River Basin by manual and automatic methods}

\begin{abstract}
In W estern Bahia, where the Fêmeas River Basin is located, groundwater has been increasingly utilized, given the low density of drainage in the region and the growing demand for water, mainly irrigation projects. The objectives of this study are based on flow data to calculate the recharge of groundwater in the Femeas basin using two methods: Arnold \& Allen (1999) and Rutledge \& Daniel (1994), in the period of 1977 to 2007. The mean annual precipitation in the Fêmeas River Basin in the studied period was $1121.83 \mathrm{~mm}$ year ${ }^{-1}$ and the mean stream flow was $50.28 \mathrm{~m}^{3} \mathrm{~s}^{-1}$ year-1. Both showed a significant decreasing trend over the years. The mean base flow found for the basin was $257.41 \mathrm{~mm}$ year ${ }^{-1}$. The rates of recharge were $4 \%$ of total P (Arnold \& Allen, 1999), and 17\% (Rutledge \& Daniel, 1994). Considering the basin discharge (around $250 \mathrm{~mm}$ year-1), the latter method seems to be better in estimating recharge.
\end{abstract}

Key words: groundwater recharge, hydrograph recession, hydrology 


\section{INTRODUÇÃO}

As águas subterrâneas apresentam valor estratégico em muitas regiões, há vista serem consideradas, em outros locais, como único recurso disponível devido à escassez da água superficial ou até mesmo à sua total indisponibilidade. Na região do oeste baiano, onde se encontra a bacia do Rio das Fêmeas, a água subterrânea tem sido progressivamente procurada como fonte de abastecimento, em especial pela baixa densidade de drenagem do local e em virtude de alguns rios da região já terem atingido o limite legal máximo outorgável (Gaspar, 2006). $\mathrm{O}$ conhecimento da recarga do aquífero é um subsídio à otimização da exploração das águas subterrâneas (Melo et al., 2005).

A recarga da água subterrânea pode ser definida como o fluxo de água descendente que alcança o nível da água de um aquiífero livre, formando uma reserva de água adicional para as águas subterrâneas. A recarga pode acontecer de maneira natural, pela precipitação, pelos rios, canais e ainda por fenômenos artificiais introduzidos pelo homem, pelas técnicas de irrigação e pela urbanização (Melo et al., 2005).

Em muitos casos a recarga da água subterrânea é estimada através das flutuações ocorridas no nível de água em poços de observações (Mau \& Winter, 1997). A estimativa da recarga também pode ser realizada por meio de dados de vazão, pela separação de hidrogramas, que também já vêm sendo objeto de estudo há mais de um século; o mais comumente utilizado é a estimação do escoamento de base (Chen \& Lee, 2003). Este método estima dados contínuos ou dados diários do escoamento de base dos hidrogramas de vazão, por uma variedade de métodos manuais (Barnes, 1939) ou automáticos (Mau \& Winter, 1997; Rutledge, 1998).

Uma alternativa para se estimar os dados do escoamento de base é o método do deslocamento da curva de recessão, também denominado método de Rorabaugh, e consiste de uma série de cálculos visando estimar a recarga total para cada pico da vazão (Rorabaugh, 1964; Rutledge \& Daniel, 1994; Chen \& Lee, 2003). Objetivando diminuir a subjetividade das análises manuais e aumentar a velocidade das análises, Rutledge (1998) propôs uma série de programas, RECESS, RORA e PART, que automatizam o método do deslocamento da curva de recessão.

Em muitos métodos, a separação do escoamento de base do hidrograma total da vazão está baseada na análise da recessão do escoamento enquanto as recessões são influenciadas por diversos aspectos, como: evapotranspiração, armazenamento no solo, a ocorrência de vários reservatórios de armazenagem ao invés de um, recarga da camada de zona insaturada, variações na recarga, variações na espessura do aquífero, penetração do rio e precipitação antecedente (Peters \& van Lanen, 2005).

Segundo Tucci (2009), o hidrograma é a denominação dada ao gráfico entre a vazão e o tempo, sendo este resultado da interação de todos os componentes do ciclo hidrológico entre a ocorrência da precipitação e a vazão na bacia hidrológica. $\mathrm{O}$ hidrograma atinge o máximo de acordo com a distribuição da precipitação apresentando, a seguir, a recessão em que pode ser observado um ponto de inflexão o qual, por sua vez, caracteriza o fim do escoamento superficial e a predominância do escoamento de base.

O hidrograma pode ser dividido em três partes principais: ascensão, altamente correlacionada com a intensidade da precipitação; região do pico, próximo ao valor máximo, quando o hidrograma começa a mudar de inflexão devido à diminuição da precipitação e/ou ao amortecimento da bacia, terminado quando finda o escoamento superficial apresentando, posteriormente, apenas o escoamento subterrâneo; recessão, fase em que só o escoamento subterrâneo está contribuindo para a vazão total do rio (Tucci, 2009).

A separação total do hidrograma em escoamento de base (base flow), que é a descarga natural da água subterrânea; escoamento superficial (direct runoff), corresponde à água que corre pela superfície da terra e escoamento subsuperficial (interflow), que consiste na água que flui sob a terra mas não faz parte da água subterrânea; geralmente é considerada satisfatória para o planejamento e para o manejo dos recursos hídricos (Askoy et al., 2009).

Objetivou-se, a partir de dados de vazão, calcular a recarga da água subterrânea por meio de métodos manuais e automáticos de recarga.

\section{Material e MÉTOdos}

A Bacia do Rio das Fêmeas está localizada a oeste do Estado da Bahia e faz parte da Bacia do Rio Grande, afluente da margem esquerda do Médio Rio São Francisco, entre os paralelos $11^{\circ} 15^{\prime}$ e $13^{\circ} 30^{\prime} \mathrm{S}$ e meridianos $43^{\circ} 45^{\prime}$ e $46^{\circ} 30^{\prime} \mathrm{W}$, com área de $5.825 \mathrm{~km}^{2}$ (Pimentel et al., 2000).

Os dados pluviométricos e fluviométricos analisados foram obtidos do HIDROWEB - ANA. As estações pluviométricas utilizadas foram: Roda Velha - 01245015, Derocal - 01245005 e Cabeceira Grande - 01245016. Para os dados fluviométricos analisou-se a estação Derocal - 46455000. Os dados utilizados correspondem aos anos hidrológicos de 1977/1978 a 2006/2007 (de primeiro de agosto a trinta e um de julho).

Para estimar a recarga da água subterrânea do aquifero da bacia do Rio das Fêmeas a partir de dados de vazão, utilizaramse duas metodologias, ambas baseadas no deslocamento da curva de recessão, em que a primeira consiste no método manual de Arnold \& Allen (1999) e a segunda ao método automático de Rutledge \& Daniel (1994).

\section{Método do deslocamento da curva de recessão}

Este método é baseado no deslocamento para cima da curva de recessão da descarga da água subterrânea que ocorre devido ao evento de recarga (Arnold e Allen, 1999). Quando o escoamento superficial é negligenciável o fluxo da descarga total da água subterrânea pode ser baseado em uma recessão antecedente (Chen \& Lee, 2003). A proposta empírica do tempo de base do escoamento superficial $(\mathrm{N})$ como função da área de drenagem, pode ser obtida pela Eq. 1, seguinte (Rutledge \& Daniel, 1994):

$$
\mathrm{N}=\mathrm{A}^{0,2}
$$


em que:

$\mathrm{N}$ - corresponde ao tempo de base do escoamento superficial, dias

A - nárea de drenagem da estação fluviométrica, milhas quadradas

A área do hidrograma de vazão só pode ser considerada descarga total da água subterrânea se for precedida de um período de recessão igual ou maior que N (Chen \& Lee, 2003).

A descarga da água subterrânea para o rio é expressa por Rorabaugh (1964) como função complexa do tempo após a recarga, função passível de ser aproximada depois do "tempo crítico", pela Eq. 2:

$$
\mathrm{Tc}=\frac{0,2 \mathrm{a}^{2} \mathrm{~S}}{\mathrm{TR}}
$$

donde:

Tc - igual ao tempo crítico, a equivale à distância média do rio até o divisor hidrológico

S - coeficiente de armazenamento

TR - transmissividade

Porém, para se obter o tempo crítico com uma função do índice de recessão (K) deve-se combinar a Eq. 2 com a Eq. 3 (Chen \& Lee, 2003):

$$
\mathrm{K}=\frac{0,933 \mathrm{a}^{2} \mathrm{~S}}{\mathrm{TR}}
$$

Resolvendo e substituindo ( $\left.\mathrm{a}^{2}\right) \mathrm{S} / \mathrm{TR}$ na Eq. 2, Tc pode ser expresso como:

$$
\mathrm{TC}=0,2144 \mathrm{~K}
$$

Rorabaugh (1964) e Rutledge \& Daniel (1994) demonstraram que a descarga total potencial da água subterrânea para o rio depois do tempo crítico do pico da vazão é aproximadamente igual à metade do volume total de água que recarrega o sistema de água subterrânea durante o período de pico. Assim, pelo princípio da superposição a recarga total pode ser calculada pela seguinte expressão (Chen \& Lee, 2003):

$$
\mathrm{R}=\frac{2\left(\mathrm{Q}_{2}-\mathrm{Q}_{1}\right) \mathrm{K}}{2,3026}
$$

donde:

$\mathrm{R}$ - volume total da recarga devido ao evento, $\mathrm{ft}^{3}$

$\mathrm{Q}_{1}$ - descarga da água subterrânea no tempo crítico extrapolada do pré-evento da recessão da vazão, $\mathrm{ft}^{3} \mathrm{~s}^{-1}$

$\mathrm{Q}_{2}$ - descarga da água subterrânea no tempo crítico extrapolada do pós-evento da recessão da vazão, $\mathrm{ft}^{3} \mathrm{~s}^{-1}$ (Figura 1)

\section{Método manual de Arnold \& Allen (1999)}

A metodologia de Arnold \& Allen (1999) utilizada neste estudo, consistiu das seguintes etapas:

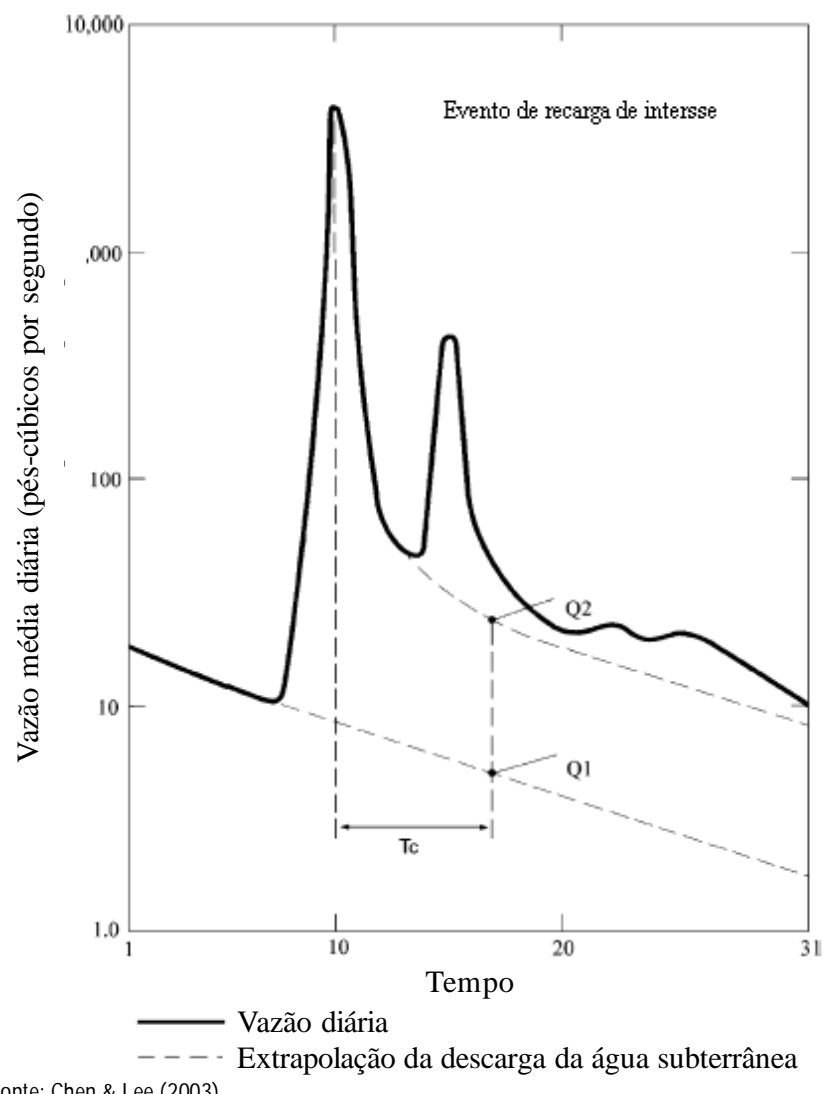

Figura 1. Processo de uso do método do deslocamento da curva de recessão para estimar a recarga da água subterrânea em resposta a um evento de recarga

1. Separação do escoamento de base: para separar o escoamento de base do hidrograma total da vazão, utilizou-se a técnica do filtro digital, também usada por outros autores (Lin et al., 2007; Nathan \& McMahon, 1990; Askoy et al., 2009). A equação do filtro é:

$$
\mathrm{q}_{\mathrm{t}}=\beta \mathrm{q}_{\mathrm{t}-1}+\frac{1+\beta}{2} \times\left(\mathrm{Q}_{\mathrm{t}}-\mathrm{Q}_{\mathrm{t}-1}\right)
$$

em que:

qt - parte filtrada correspondente ao escoamento superficial no tempo t, um dia

Q - dado original de vazão

$\beta$ - um parâmetro do filtro $(0,925)$, determinado por Nathan $\&$ McMahon (1990). O escoamento de base $\left(b_{t}\right)$ foi obtido pela Eq.7 (Arnold \& Allen, 1999):

$$
\mathrm{b}_{\mathrm{t}}=\mathrm{Q}_{\mathrm{t}}-\mathrm{q}_{\mathrm{t}}
$$

O filtro pode ser passado três vezes nos dados de vazão: para frente, para trás e novamente para frente, dependendo da seleção requerida pelo usuário (Arnold \& Allen, 1999). Para o presente estudo só foi realizada uma passagem do filtro, pelos dados de vazão.

3. Recarga da água subterrânea: o método desenvolvido consistiu em uma modificação do método do deslocamento da curva de recessão, pelas seguintes etapas: 
Etapa 1: Passar o filtro da Eq. 6 nos dados de vazão, para cada ano hidrológico e obter o fluxo de base;

Etapa 2: Encontrar o ponto em que a curva do escoamento de base se encontra com a curva da vazão (Ponto A na Figura 2) e calcular a constante de recessão $(\alpha)$ :

$$
\alpha=\ln \frac{\left(\frac{\mathrm{q}_{\mathrm{N}}}{\mathrm{q}_{\mathrm{a}}}\right)}{\mathrm{N}}
$$

donde:

$q_{n}$ e $q_{A}$ correspondem à vazão nos pontos $N$ e $A$, respectivamente. Visando estimar á de maneira mais correta, o período de recessão $(\mathrm{N})$ deve ser de pelo menos 10 dias.

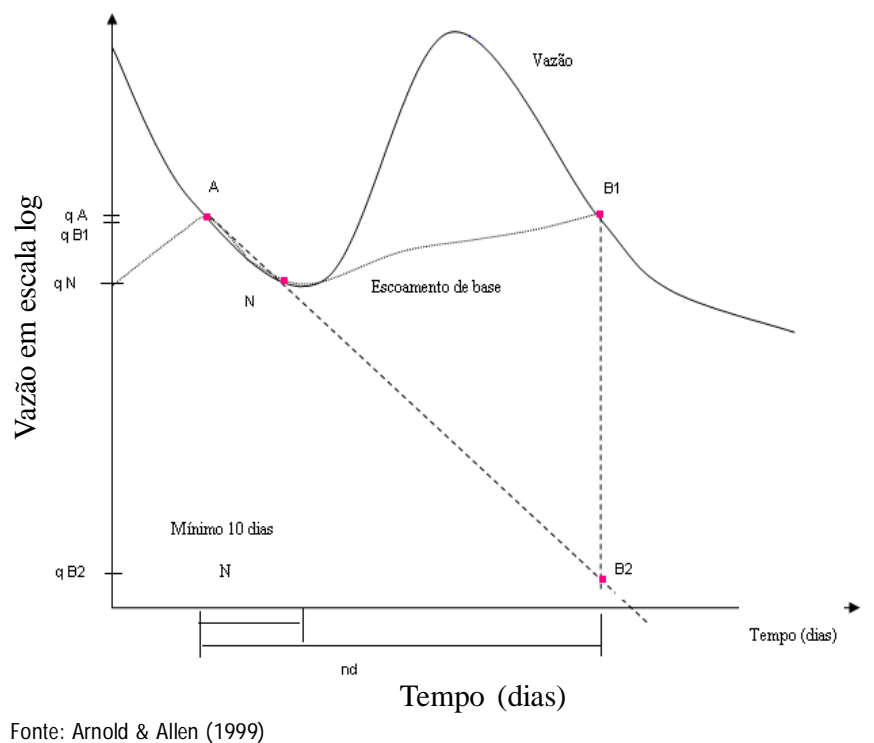

Figura 2. Técnica para estimar a recarga a partir de dados de vazão

Etapa 3: Encontrar o próximo ponto no qual a curva do escoamento de base se encontra com a curva da vazão (Ponto $B_{1}$ na Figura 2).

Etapa 4: Extrapolar a curva de recessão do ponto A para o ponto $\mathrm{B}_{2}$ e calcular o valor de $\mathrm{q}_{\mathrm{B} 2}$.

$$
\mathrm{q}_{\mathrm{B} 2}=\frac{\mathrm{q}_{\mathrm{A}}}{\mathrm{e}^{(\mathrm{nd} \times \alpha)}}
$$

donde:

$\mathrm{q}_{\mathrm{B} 2}$ é a vazão no ponto $\mathrm{B}_{2}$ e nd é o número de dias entre os pontos A e B.

Etapa 5: Calcular a recarga da água subterrânea para o período entre os pontos A e B, por meio das equações:

$$
\begin{gathered}
\mathrm{R}\left[\left(\mathrm{m}^{3} / \mathrm{s}\right) / \mathrm{dia}\right]=\left(\mathrm{q}_{\mathrm{A}}-\mathrm{q}_{\mathrm{B} 2}\right) \times \mathrm{nd} \\
\mathrm{R}\left(\mathrm{m}^{3}\right)=\mathrm{R}\left[\left(\mathrm{m}^{3} / \mathrm{s}\right) / \mathrm{dia}\right] \times 3600 \times 24
\end{gathered}
$$

$$
\mathrm{R}\left(\frac{\mathrm{mm}}{\mathrm{ano}}\right)=\frac{\left[\mathrm{R}\left(\mathrm{m}^{3}\right) \times 1000\right]}{6300 \times 10^{6}}
$$

Etapa 6: Repetir cada etapa para cada período de recessão do escoamento de base.

\section{Método automático de Rutledge \& Daniel (1994)}

A metodologia de Rutledge \& Daniel (1994) foi realizada com base no método do deslocamento da curva de recessão, cujo processo pode ser observado na Figura 1. Para determinar o índice de recessão padrão da bacia utilizou-se o programa computacional RECESS e, para calcular a recarga da água subterrânea a partir de dados de vazão, foi utilizado o programa RORA, ambos desenvolvidos por Rutledge (1998).

Para verificar as tendências das séries temporais entre as variáveis analisadas e os anos hidrológicos, realizou-se a correlação com base em Salas (1992). O número de picos utilizados em cada metodologia de recarga também serviu para comparar os resultados.

\section{RESULTADOS E DISCUSSÃO}

A precipitação média anual encontrada para a bacia do Rio das Fêmeas foi de 1121,83 mm ano ${ }^{-1}$, com máxima de 1585,40 mm e a mínima de $662,83 \mathrm{~mm}$ para os anos hidrológicos de 1977/1978 e 2004/2005, respectivamente. A vazão anual média foi de $50,28 \mathrm{~m}^{3} \mathrm{~s}^{-1}$ ano $^{-1}$, o que corresponde com $24,26 \%$ da precipitação média, com máxima de $61,47 \mathrm{~m}^{3} \mathrm{~s}^{-1}$ para ano de 1979/1980, e a mínima foi de $41,06 \mathrm{~m}^{3} \mathrm{~s}^{-1}$ para o ano de 2002/ 2003. Observou-se que correram quedas significativas pelo testT da precipitação e da vazão, ao longo dos anos hidrológicos.

Santos et al. (2010) analisaram a relação entre uso do solo e comportamento hidrológico na bacia hidrográfica do Ribeirão João Leite, GO, no período de 1979 a 2005, e também observaram tendência de redução da precipitação, do deflúvio e do escoamento superficial.

A Figura 3 apresenta as precipitações e vazões médias anuais do Rio das Fêmeas para os anos hidrológicos de 1977/1978 a 2006/2007.

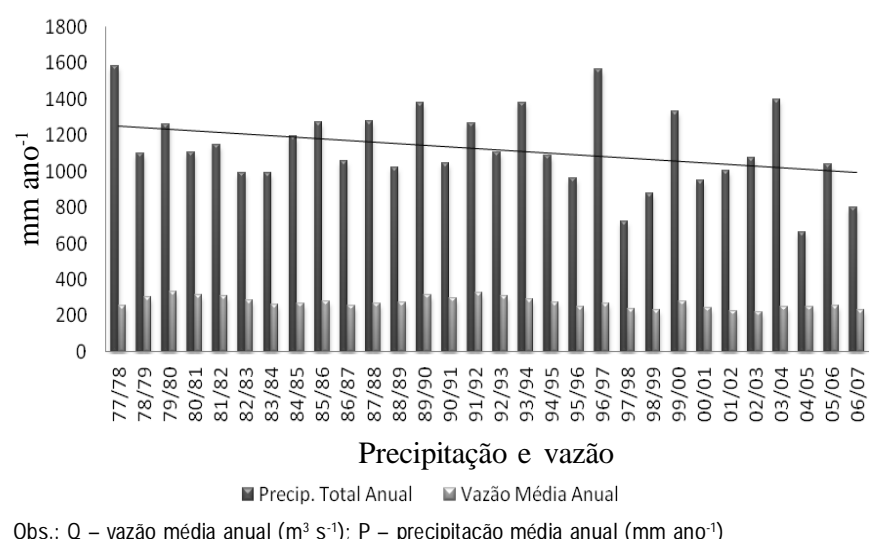

Figura 3. Precipitações e vazões médias anuais do Rio das Fêmeas para os anos hidrológicos de 1977/1978 a $2006 / 2007$ 
A metodologia de Arnold \& Allen (1999) além de calcular a recarga da água subterrânea também permite a separação do escoamento de base do hidrograma da vazão por meio da técnica do filtro digital, assim como para a região do Rio das Fêmeas, no período de 1977/1978 a 2006/2007, quando se obteve um escoamento de base médio de $257,41 \mathrm{~mm}^{2} \mathrm{ano}^{-1}$, correspondendo com $94,57 \%$ da vazão e com $22,95 \%$ da precipitação média, evidenciando o que foi obtido nos estudos de Gaspar (2006) na região em que se encontra a bacia do Rio das Fêmeas, por apresentar baixa densidade de drenagem atribuída à alta capacidade de infiltração da cobertura dos latossolos e dos arenitos do Grupo Urucuia.

Peter \& van Lanen (2005) desenvolveram um novo método de filtro para separar o escoamento de base a partir de dados de vazão, níveis da água subterrânea e excesso da precipitação e obtiveram, para a estação Pangbourne na bacia Pang - Reino Unido, no período de 1973 a 1997, uma porcentagem de escoamento de base de 67,3 a 77,4\% do hidrograma de vazão.

A recarga obtida pela metodologia de Arnold \& Allen (1999) apresentou média de 47,79 $\mathrm{mm}_{\text {ano }}^{-1}$ correspondendo com 4,26\% da precipitação. A recarga máxima foi de $134,41 \mathrm{~mm}^{-1} \mathrm{ano}^{-1} \mathrm{e}$ mínima de 5,25 mm ano $^{-1}$, para os anos de 1991/1992 e de 1995/ 1996, respectivamente.

No método de Rutledge \& Daniel (1994) obteve-se, pelo programa RECESS, um índice de recessão médio para a bacia, de 119,95 dias por ciclo de log, para os trinta anos de análise de dados de vazão. Com a utilização do programa RORA foi obtida uma recarga média de $256,53 \mathrm{~mm}^{2} \mathrm{ano}^{-1}$, correspondendo com $22,87 \%$ da precipitação média. A recarga máxima foi de 303,53 mm ano ${ }^{-1}$ para o ano de $1989 / 1990$ e a mínima foi de 198,37 $\mathrm{mm}$ ano $^{-1}$, no ano de 1982/1983.

Realizando o balanço hidrogeológico para o período de 1982 a 2002 na zona vadosa da área da bacia hidrogeológica do Sistema Aquifero Urucuia, na região de Correntina, BA, Gaspar (2006) obteve precipitação média de $1.240,87 \mathrm{~mm}^{2} \mathrm{ano}^{-1} \mathrm{com}$ recarga de 278,98 $\mathrm{mm}^{2} \mathrm{ano}^{-1}$, correspondendo com $24,10 \% \mathrm{em}$ relação à precipitação média.

A Figura 4 apresenta a separação do escoamento de base do hidrograma de vazão, segundo a metodologia de Arnold \& Allen (1999) para o ano hidrológico de 1977/1978.

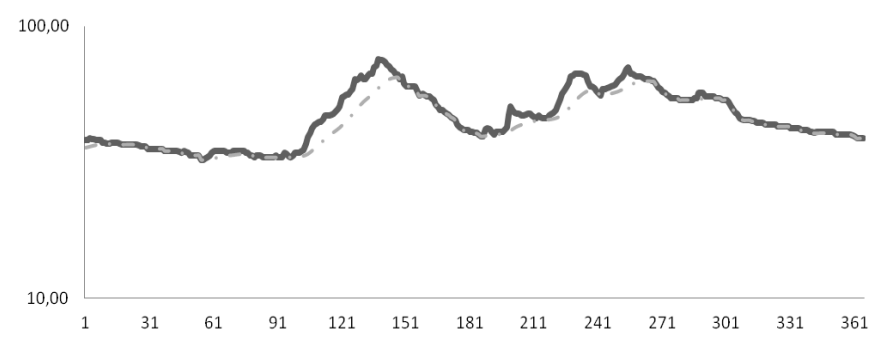

Obs.: Q - vazão média anual $\left(m^{3}\right.$ dia-1 $\left.^{-1}\right) ; q$ - escoamento de base $\left(m^{3}\right.$ dia-1)

Figura 4. Separação do escoamento de base do hidrograma de vazão segundo a metodologia de Arnold \& Allen (1999) no ano hidrológico de 1977/1978

Chen \& Lee (2003) também estimaram a recarga da água subterrânea pelo método do deslocamento da curva de recessão, conforme Rutledge \& Daniel (1994), para oito estações fluviométricas em Taiwan e obtiveram, para a estação Ziu-Chian Bridge com área de drenagem de $2.988,88 \mathrm{~km}^{2}$, um índice de recessão de 17,2 dias por ciclo de log e uma recarga anual da água subterrânea de 1,94 t.

Szilagyi et al. (2003) observaram, analisando a recarga em Nebraska, USA, que na região sudoeste apenas $1 \%$ de toda a média da precipitação anual recarregou a água subterrânea enquanto na porção sudeste do Estado a recarga foi maior que $13 \%$ da precipitação anual, diferença que pode ser devida sobretudo ao fato da umidade do solo na porção leste ser próxima da capacidade de campo no ano de grande precipitação e por apresentar baixo clima árido do local.

A Figura 5 apresenta os valores das recargas médias mensais obtidas pelo método de Rutledge \& Daniel (1994), para a Bacia do Rio das Fêmeas, no período de 1977 a 2007, além dos valores da precipitação média mensal e a vazão mensal.

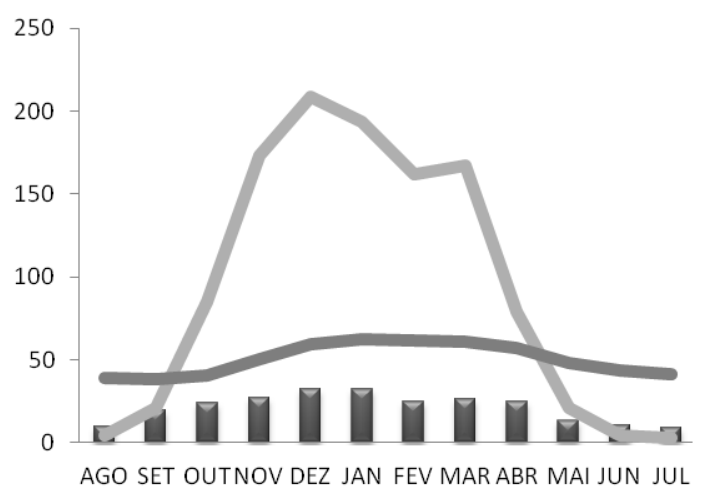

Tempo (meses)

Obs.: RRD - recargas médias mensais obtidas pelo método de Rutledge \& Daniel (1994) (mm mês ${ }^{-1}$ ), $P$ - precipitação média mensal (mm mês $\left.{ }^{-1}\right) ; Q$ - vazão mensal $\left(\mathrm{m}^{3}\right.$ mês $\left.^{-1}\right)$

Figura 5. Recargas médias mensais obtidas pelo método de Rutledge \& Daniel (1994), para a bacia do Rio das Fêmeas, no período de 1977 a 2007, e os valores da precipitação média mensal e a vazão mensal

As recargas mensais médias obtidas pelo método automático obtiveram máximas de 32,39 e 31,94 $\mathrm{mm} \mathrm{mês}^{-1}$, para os meses de dezembro e janeiro, respectivamente; as mínimas foram para os meses de julho e agosto, com 9,28 e 9,85 mm mês ${ }^{-1}$. Os meses de máximas e mínimas também correspondem aos meses de máximas e mínimas das precipitações médias mensais.

Segundo Wittenberg \& Sivapalan (1999), somente uma pequena fração da precipitação atua diretamente na recarga da água subterrânea podendo ser superior a 30\% em regiões de clima temperado, na Europa Central, e menor que 5\% para condições semiáridas, no Oeste Australiano.

A Tabela 1 apresenta os valores escoamento de base e das recargas obtidas para os métodos de Arnold \& Allen (1999) e de Rutledge \& Daniel (1994), na bacia do Rio das Fêmeas, nos períodos de 1977/1978 a 2006/2007.

Melo et al. (2005) avaliaram a recarga da água subterrânea para o aquifero Açu, na borda sudoeste da Bacia Potiguar a oeste do Estado do Rio Grande do Norte, com área de 1.320 $\mathrm{km}^{2}$, sendo igual a 54 milhões de $\mathrm{m}^{3}$ ano $^{-1}$. Estimou-se a recarga comparando-se diferentes metodologias, como os métodos 
Tabela 1. Valores do escoamento de base e das recargas obtidas para os métodos de Arnold \& Allen (1999) - RAA, e de Rutledge $\&$ D aniel (1994) - RRD

\begin{tabular}{|c|c|c|c|}
\hline Ano & $q$ & RAA & RRD \\
\hline $77 / 78$ & 239,97 & 47,57 & 281,94 \\
\hline $78 / 79$ & 285,92 & 77,73 & 302,26 \\
\hline $79 / 80$ & 312,10 & 103,19 & 214,88 \\
\hline $80 / 81$ & 294,10 & 61,90 & 277,62 \\
\hline $81 / 82$ & 274,99 & 67,83 & 241,55 \\
\hline $82 / 83$ & 273,56 & 43,60 & 198,37 \\
\hline $83 / 84$ & 254,49 & 8,38 & 251,46 \\
\hline $84 / 85$ & 254,57 & 21,36 & 256,29 \\
\hline $85 / 86$ & 260,29 & 24,29 & 270,37 \\
\hline $86 / 87$ & 243,30 & 36,26 & 255,23 \\
\hline $87 / 88$ & 255,36 & 28,71 & 204,98 \\
\hline $88 / 89$ & 256,96 & 72,49 & 293,88 \\
\hline $89 / 90$ & 295,02 & 125,00 & 303,53 \\
\hline $90 / 91$ & 284,96 & 71,98 & 269,49 \\
\hline $91 / 92$ & 304,67 & 134,41 & 289,31 \\
\hline $92 / 93$ & 295,81 & 67,72 & 278,89 \\
\hline $93 / 94$ & 275,50 & 35,61 & 262,38 \\
\hline $94 / 95$ & 262,14 & 20,91 & 265,68 \\
\hline $95 / 96$ & 241,24 & 5,25 & 246,89 \\
\hline $96 / 97$ & 254,18 & 67,56 & 277,88 \\
\hline $97 / 98$ & 228,42 & 19,78 & 230,63 \\
\hline $98 / 99$ & 217,99 & 27,33 & 241,55 \\
\hline $99 / 00$ & 263,92 & 27,23 & 281,94 \\
\hline $00 / 01$ & 232,98 & 27,55 & 246,89 \\
\hline $01 / 02$ & 214,38 & 26,88 & 231,90 \\
\hline $02 / 03$ & 208,14 & 40,58 & 217,68 \\
\hline $03 / 04$ & 235,15 & 12,20 & 265,68 \\
\hline $04 / 05$ & 237,31 & 34,07 & 256,79 \\
\hline $05 / 06$ & 242,17 & 70,03 & 241,55 \\
\hline 06/07 & 222,59 & 26,26 & 238,50 \\
\hline Média & 257,41 & 47,79 & 256,53 \\
\hline Desvio padrão & 27,80 & 32,67 & 27,41 \\
\hline Máximo & 312,10 & 134,41 & 303,53 \\
\hline Mínimo & 208,14 & 5,25 & 198,37 \\
\hline
\end{tabular}

do balanço hidroclimatológico, variação do nível da água, Lei de Darcy aplicada ao meio poroso saturado e balanço de cloreto.

As correlações realizadas com base em Salas (1992) para verificar as tendências das séries temporais realizadas entre a precipitação, a vazão e as recargas obtidas pelos métodos de Arnold \& Allen (1999) e de Rutledge \& Daniel (1994) com os anos hidrológicos, sem exceção, apresentaram queda significativa ao longo dos anos. Obtiveram-se a maior correlação para a vazão e a menor para o método de Rutledge \& Daniel (1994). A Tabela 2 apresenta os coeficientes de correlação para as séreis temporais de precipitação, vazão e as recargas obtidas entre as diferentes metodologias.

Tabela 2. Coeficientes de correlação para as séries temporais de precipitação, vazão e as recargas obtidas entre as diferentes metodologias

\begin{tabular}{lcccc}
\hline & $\mathbf{P}$ & $\mathbf{Q}$ & RAA & RRD \\
Coeficiente de correlação & $-0,351$ & $-0,635$ & $-0,308$ & $-0,159$ \\
Anos da série & 30 & 30 & 30 & 30 \\
TC & $1,980 * *$ & $4,345^{* *}$ & $1,711^{* *}$ & $0,851^{*}$
\end{tabular}

P - precipitação média anual $\left(\mathrm{mm}^{2} \mathrm{no}^{-1}\right) ; \mathrm{Q}$ - vazão média anual $\left(\mathrm{m}^{3} \mathrm{~s}^{-1}\right) ; \mathrm{RAA}=$ Metodologia de Arnold \& Allen (1999) $\left(\mathrm{mm}^{2} \mathrm{ano}^{-1}\right) ; \mathrm{RRD}=$ Metodologia de Rutledge \& Daniel $(1994)\left(\mathrm{mm} \mathrm{ano}^{-1}\right)$; $*$ significativo a $5 \%$; ** significativo a $99 \%$
Comparando os eventos de recarga analisados pelas duas metodologias, conclui-se que o método automático de Rutledge \& Daniel (1994) analisou 728 picos de vazão (Figura 6), valor oito vezes maior que o número de picos analisados pelo método de Arnold \& Allen (1999) (92 picos) devido, sobretudo ao fato da metodologia de Arnold \& Allen (1999) restringir um número mínimo de dias de recessão para se calcular o evento de recarga e por se tratar de método manual de análise.

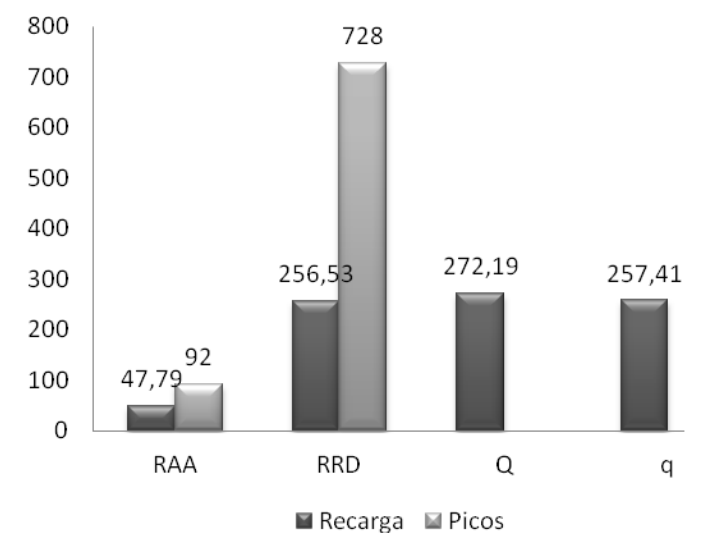

Obs.: RAA - recargas médias anuais obtidas pelo método de Arnold \& Allen (1999) ( $\mathrm{mm}^{2} \mathrm{an}^{-1}$ ): RRD - recargas médias anuais obtidas pelo método de Rutledge \& Daniel (1994) ( $\mathrm{mm}^{2} \mathrm{ano}^{-1}$ ): Picos - número de picos analisados; $\mathrm{Q}$ - vazão média anual $\left(\mathrm{m}^{3}\right.$ ano-1) e $\mathrm{q}$ - escoamento de base $(\mathrm{mm}$ ano-1)

Figura 6. Relação entre as médias de recarga, número de picos, vazão e escoamento de base

Como a taxa de recarga atual nunca é totalmente conhecida para cada localização, vários métodos de recarga são utilizados e os resultados comparados. Nenhum método pode ser considerado o melhor para estimar a recarga, em virtude da: variabilidade espacial e temporal nas diversas variáveis independentes; limitações inerentes de cada modelo; limitações na disponibilidade dos dados de entrada da área analisada e variabilidade nos usos e aplicações da recarga estimada (Delin et al., 2007).

Na Figura 6 se observam a relação entre os valores médios obtidos pelas duas metodologias de recarga, o número de picos analisados entre as metodologias, a vazão e o escoamento de base.

\section{CONClusões}

1. Ocorreram quedas significativas da precipitação e da vazão, ao longo dos anos hidrológicos.

2. Os Latossolos da região apresentaram alta eficiência na infiltração, pelo alto valor do escoamento de base.

3. O método automático de Rutledge e Daniel foi o que se apresentou mais satisfatório por se aproximar dos valores de escoamento de base (descarga) médio anual, enquanto o método manual de Arnold e Allen o subestimou.

\section{LITERATURA CITADA}

Aksoy, H.; Kurt, I.; Eris, E. Filtered smoothed minima baseflow separation method. Journal of Hydrology, v.372, p.94-101, 2009. 
Arnold, J. G.; Allen, P. M. Automated methods for estimating baseflow and ground water recharge from streamflow records. Journal of the American Water Resources Association, v.35, p.411-424, 1999.

Barnes, B. S. The structure of discharge recession curves. Trans Am Geophys Union, v. 20, p.721-725, 1939.

Chen, W.; Lee, C. Estimating ground-water recharge from steamflow records. Environmental Geology, v.44, p.257-265, 2003.

Delin, G. N.; Healy, R. W.; Lorenz, D. L.; Nimmo, J. R. Comparison of local to regional-scale estimates of ground-water recharge in Minnesota, USA. Journal of Hydrology, v.334, p.231-249, 2007.

Gaspar, M. T. P. Sistema aquífero Urucuia: Caracterização regional e proposta de gestão. Brasília: UnB, 2006. 157p. Tese Doutorado

Lin, K.; Guo, S.; Zhang, W.; Liu, P. A new baseflow separation method based on analytical solutions of the horton infiltration capacity curve. Hydrological Processes, v.21, p.1719-1736, 2007.

Mau, D. P.; Winter, T.C. Estimating ground-water recharge from streamflow hydrographs for a small mountain watershed in a temperate humid climate, New Hampshire, USA. Ground Water, v.35, p.291-304, 1997.

Melo, J. G.; Stein, P.; Vasconcelos, M. B.; Silva, F. H. R. Fatores condicionantes na recarga do aquifero Açu na borda sudoeste na Bacia Potiguar, RN. Águas Subterrâneas, v.19, p.105-122, 2005.

Nathan, R. J.; McMahon, A. Evaluation of automated tecniques for base flow and recession analyses. Water Resources Research, v.26, p.1465-1473, 1990.

Peters, E.; van Lanen, H. A. J. Separation of base flow from streamflow using groundwater levels - Illustrated for the Pang catchment (UK). Hydrological Processes, v.19, p.921936, 2005.
Pimentel, A. L.; Aquino, R. F.; Silva, R. C. A.; Vieira, C. M. B. Estimativa da recarga do aquifero Urucuia na sub-bacia do rio das Fêmeas - Oeste da Bahia, utilizando separação de hidrogramas. In: Congresso sobre Aproveitamento e Gestão de Recursos Hídricos em Países de Idioma Português, Rio de Janeiro: ABES/AIDIS/ABRH, 2000. p.27-37.

Rorabaugh, M. I. Estimating changes in bank storage and ground-water contribution t streamflow. International Association of Scientific Hydrology, v.63, p.432-441, 1964.

Rutledge, A. T. Computer programs for describing the recession of ground-water discharge and for estimating mean groundwater recharge and discharge from streamflow data - update. Washingyon: U. S. Geological Survey Water-Resources Investigations Report 98-4148. 1998.43p.

Rutledge, A. T.; Daniel, C.C. Testing an automated method to estimate ground-water recharge from streamflow records. Ground Water, v.32, p.180-189, 1994.

Salas, J. D. Analysis and modeling of hydrologic time series. In: Maidment, D. R. (ed.). Handbook of hydrology. New York: McGraw-Hill, Inc. 1992. cap. 19.

Santos, E. H. M.; Griebeler, N. P.; Oliveira, L. F. C. Relação entre uso do solo e comportamento hidrológico na Bacia Hidrográfica do Ribeirão João Leite. Revista Brasileira de Engenharia Agrícola e Ambiental. v.14, p.826-834, 2010.

Szilagyi, J.; Harvey, F. E.; Ayers, J. F. Regional estimation of base recharge to ground water using water balance and a base-flow index. Ground Water, v.41, p.504-513, 2003.

Tucci, C. E. M. Hidrologia: Ciência e aplicação. Porto Alegre: UFRGS, 2009. 944p.

Wittenberg, H.; Sivapalan, M. Watershed groundwater balance estimation using streamflow recession analysis and baseflow separation. Journal of Hydrology, v.219, p.20-33, 1999. 